\title{
What do we think about our training?*
}

\author{
David Castle, Anne Reeve, Louise Ivinson and Simon Hampson
}

\begin{abstract}
A working party of the Collegiate Trainees' Committee of the Royal College of Pyychiatitists sent a questionnaire to all trainees taking Part II of the MRCPoych examination in October 1992, asking about their satistaction with various aspects of their training. Amost $70 \%$ rated their training as 'good' or 'excellent', but specilic areas showed wide variation. Cognilive/behovioural poychotherapy, fanlily therapy, research, the management of dengerous patients and the use of ECT were all highIfohted as areas in need of improvement. The working party make recommendations in the light of these indings.
\end{abstract}

Psychlatric trainees are increasingly expected to be comfortable not only with a very broad range of clinical skills in psychiatry but also with the scientific basis of our discipline. There is pressure on trainees to do research and to publish scientific papers. Also, in the face of drastic changes to the health service and to the provisions for community care, future consultant psychiatrists are well advised to acquire management skills.

The College seeks to ensure individual trainees meet the requisite standards of knowledge by having them take the MRCPsych exam. To ensure training schemes provide appropriate and adequate training opportunities, regular approval visits are made. This paper gives the results of a Working Party of the Colleglate Trainees' Committee (CTC) which sought to gauge how satisfied trainees are with various aspects of training, and to assess trainees' perception of the functioning and efficacy of approval visits.

\section{The study and findings}

A confidential questionnaire was sent to all 317 trainees who took Part II of the MRCPsych exam in October 1992. This group was chosen on the basis that they would have had wide experience of the training schemes and so be able to make an overall judgement of their quality. The ques-

"Report of a working party of the Collegiate Trainees Committee. tionnaire (copies available on request from the authors) requested a rating of various aspects of training on a four-point scale from 'excellent' through 'good' and 'adequate', to 'poor'. One hundred and thirty-seven replies (43\%) were received. To ensure confidentiality, respondents were not asked to record their name or the name of their training scheme; follow-up of nonrespondents was thus precluded.

\section{Clinical training}

Almost 70\% of trainees rated their overall training as 'good' or 'excellent'. However, ratings of specific aspects of training showed wide variation (see Table 1). The most consistently highly rated areas were adult general and old age psychiatry. More even ratings were given for forensic, child and adolescent and rehabilitation psychiatry training.

Ratings for training opportunities in psychodynamic psychotherapy were varied, around half of respondents giving a rating of 'excellent' or 'good'. However, a high proportion of respondents considered opportunities for training in cognitive/behavioural psychotherapy (68\%) and in family therapy (66\%) to be 'adequate' or 'poor'.

Regarding training in specific clinical and management skills (Table 2), most respondents appeared satisfied with training in the mental state examination (MSE), but training in interview skills was less favourably rated. Over two thirds of the respondents rated training in the use of ECT to be 'adequate' or 'poor', and there appeared a general dissatisfaction with training in the management of violence. Low ratings were also given to management training, with almost two thirds of respondents considering opportunities for training in this area 'poor'.

\section{Academic and research items}

Asked about the quality of MRCPsych lectures, fewer than $40 \%$ of respondents felt these were 'good' or 'excellent' (Table 3). Encouragingly. fewer than $10 \%$ rated the availability of study leave as 'poor', but a rather higher proportion had difficulty in obtaining study leave expenses. 
Table 1. Ratings of clinical training

\begin{tabular}{|c|c|c|c|c|}
\hline & Excellent & Good & Adequate & Poor \\
\hline $\begin{array}{l}\text { Adult general psychiatry } \\
\text { Old age psychiatry } \\
\text { Child \& adolescent psychiatry } \\
\text { Rehabilltation } \\
\text { Psychopharmacology } \\
\text { Forensic } \\
\text { Community psychiatry } \\
\text { Liaison } \\
\text { Learning disabilities } \\
\text { Substance misuse } \\
\text { Cogniltive-behovioural therapy } \\
\text { Family therapy } \\
\text { Psychodynamic psychotherapy }\end{array}$ & $\begin{array}{r}30 \% \\
31 \% \\
26 \% \\
11 \% \\
8 \% \\
18 \% \\
10 \% \\
10 \% \\
9 \% \\
12 \% \\
12 \% \\
5 \% \\
15 \%\end{array}$ & $\begin{array}{l}60 \% \\
42 \% \\
42 \% \\
42 \% \\
43 \% \\
30 \% \\
31 \% \\
37 \% \\
33 \% \\
32 \% \\
20 \% \\
29 \% \\
37 \%\end{array}$ & $\begin{array}{r}9 \% \\
21 \% \\
23 \% \\
34 \% \\
31 \% \\
21 \% \\
29 \% \\
31 \% \\
35 \% \\
33 \% \\
22 \% \\
30 \% \\
20 \%\end{array}$ & $\begin{array}{l}1 \% \\
6 \% \\
9 \% \\
13 \% \\
18 \% \\
31 \% \\
30 \% \\
22 \% \\
23 \% \\
23 \% \\
46 \% \\
36 \% \\
28 \%\end{array}$ \\
\hline
\end{tabular}

Table 2. Clinical and management skills

\begin{tabular}{lcccc}
\hline & Excellent & Cood & Adequate & Poor \\
\hline Management training & $1 \%$ & $12 \%$ & $24 \%$ & $63 \%$ \\
Training in management of violence & $1 \%$ & $16 \%$ & $37 \%$ & $46 \%$ \\
Training in use of ECT & $4 \%$ & $25 \%$ & $44 \%$ & $27 \%$ \\
Training in interview techniques & $6 \%$ & $45 \%$ & $35 \%$ & $14 \%$ \\
Training in MSE & $13 \%$ & $49 \%$ & $26 \%$ & $12 \%$ \\
\hline
\end{tabular}

Table 3. Academic and research items

\begin{tabular}{lcccc}
\hline & Excelient & Cood & Adequate & Poor \\
\hline Practical help with research & $11 \%$ & $23 \%$ & $28 \%$ & $38 \%$ \\
Quallty of MRCPsych lectures & $7 \%$ & $31 \%$ & $42 \%$ & $20 \%$ \\
Availabillty of study leave & $26 \%$ & $44 \%$ & $21 \%$ & $9 \%$ \\
Study leave expenses met & $22 \%$ & $33 \%$ & $21 \%$ & $24 \%$ \\
\hline
\end{tabular}

A worrying $40 \%$ or respondents felt avallability of practical help with research 'poor'.

\section{Opportunity for feedback and the approval visits}

Around half of the respondents rated the opportunity to discuss their progress with their tutors, or to comment on clinical attachments. 'adequate' or 'poor' (Table 4).

A large majority of trainees rated approval visits as 'adequate' or 'poor' with regard to the visit's ability to bring about significant changes to a training scheme. In other areas there were wide variations in the trainees' perceptions. Most trainees felt their freedom to discuss areas of concern and the confidentiality of their comments were at least 'adequate'. Over half of the respondents rated their knowledge of the panel's recommendations to be 'adequate' or 'poor'.

\section{Comment}

The response rate for the survey was low and this might have introduced bias. However, the fact that over $70 \%$ of the trainees rated their overall training as 'good' or 'excellent' indicates that this was not a group of trainees who were responding because they were particularly dissatisfied. Likewise, the unfavourable responses given in several areas implies that trainees seem able to pinpoint areas of concern about training.

Regarding training in the specialist areas, the results draw attention to deficits in training 


\begin{tabular}{|c|c|c|c|c|}
\hline $\begin{array}{l}\text { Discussion with clinical tutor on progress } \\
\text { Opportunity to comment on clinical attachment } \\
\text { Knowledge of function of visits } \\
\text { Freedom to discuss areas of concern with panel } \\
\text { Confidentiality regarding comments } \\
\text { Knowledge of panel's recommendations } \\
\text { Degree to which visits lead to useful improvements }\end{array}$ & $\begin{array}{r}9 \% \\
7 \% \\
8 \% \\
12 \% \\
16 \% \\
10 \% \\
3 \%\end{array}$ & $\begin{array}{l}38 \% \\
43 \% \\
40 \% \\
43 \% \\
36 \% \\
34 \% \\
22 \%\end{array}$ & $\begin{array}{l}28 \% \\
34 \% \\
32 \% \\
26 \% \\
39 \% \\
35 \% \\
48 \%\end{array}$ & $\begin{array}{r}25 \% \\
16 \% \\
20 \% \\
19 \% \\
9 \% \\
21 \% \\
27 \%\end{array}$ \\
\hline
\end{tabular}

in cognitive-behavioural therapy and family therapy. The Psychotherapy Specialist Advisory Committee (PTSAC) and the Psychotherapy Executive (Caldicott, 1992; Grant et al, 1993) have alerted the College to anxieties concerning the poor availability and quality of cognitivebehavioural therapy in many parts of the country and are to be applauded for their advice to the JCHPT to increase the number of senior registrar posts in this speciality. A similar review of family therapy training seems indicated.

There have been frequent concerns expressed by trainees about lack of training in the management of dangerous patients. This is reflected in the high number of trainees who rated this aspect of their training as poor. The CTC have responded by including it in regional trainees' days and senior registrar conferences, and more attention should be given to this by approval teams.

A large number of trainees expressed discontent about the quality of their training in the administration of ECT. This was an area of concern highlighted in the Pippard report (1988) and is another area that needs closer scrutiny during approval visits.

Today's psychiatrist requires sophisticated management skills as well as sound clinical knowledge. We would ask the College to seriously reconsider the management training of their junior doctors and future consultants. Encouragement should be given to trainees who wish to gain experience of local hospital committees, and funding for management courses should be provided.

It is disturbing that at a time when more emphasis is being placed on experience of research in psychiatry for advancement in career, a high proportion of trainees rated this area of training as poor. The delineation of research tutors within training schemes has gained some momentum and should be further encouraged.

College approval visits provide a vital opportunity for trainees to improve their schemes. The panel's recommendations may be useful levers for scheme organisers when negotiating with managers and recalcitrant consultants. It was reassuring to find that fears about the confidentiality with which trainees comments are treated are not widespread and that most trainees felt free to discuss areas of concern. However, knowledge of the panel's recommendations could be greatly improved, perhaps by circulating every trainee with an outline of the recommendations. The relatively negative view of the degree to which visits lead to improvements is worrying. These difficulties could be addressed by trainees being more outspoken about deficiencies, more explicit about suggested improvements and better informed. An established mechanism for trainees to draw the College's attention to recommendations not implemented would be welcomed.

\section{Conclusion}

We have highlighted areas of our psychiatric training which could be improved. The Collegiate Trainees' Committee looks forward to working with the rest of the College in facilitating such changes as necessary.

\section{References}

Caldicotr, F. (1992) Issues related to behavioural and cognitive psychotherapy. Psychiatric Bulletin, 16, 578579.

Grant, S., Holmes, J. \& WATSON. J. (1993) Guidelines for psychotherapy training as part of general professional psychiatric training. Psychiatric Bulletin, 17, 695-698. Also avallable as College Report CR 27.

PIPPARD, J. (1988) ECT custom and practice. Psychiatric Bulletin, 12, 473-475.

David Castle (Honorary Secretary); Anne Reeve (Vice-Chairman); Louise Ivinson and Simon Hampson (members), Collegiate Trainees Committee (1991-1993), Royal College of Psychiatrists, 17 Belgrave Square, London SW1X 8PG 